\title{
PREVALÊNCIA DA ESQUISTOSSOMOSE MANSONI E DE PARASITOSES INTESTINAIS EM ESCOLARES DA ÁREA RURAL DO MUNICÍPIO DE JABOTICATUBAS, MG, 1992-1993
}

\author{
Geraldo Cunha Cury, Paulo Guilherme de Oliveira Salles, Marcos Campos \\ Wanderley Reis, Vicente Maurício Rego, Andréa Wandalsen Arndt, Carlos \\ Batista Alves de Souza Filho, Henrique Barroso Moreira, Marcelo Sartori de \\ Abreu e Paula Mota Gonçalves Leite
}

\begin{abstract}
Estagiários do Internato Ruralda Faculdade de Medicina da UFMG realizaram levantamento da prevalência da esquistossomose mansoni e de parasitoses intestinais em 20 escolas da área rural do município de Jaboticatubas, MG. Foi feita avaliação sumária das condições de habitação e saneamento, e os escolares foram submetidos a exame clínico e parasitológico de fezes. Observou-se que $15,43 \%$ dos escolares apresentaram ovos de S. mansoni nas fezes, o que representou a parasitose de maior prevalência. Foram encontrados $13,76 \%$ de exames com a presença de $\mathrm{G}$. lamblia; $12,89 \%$ de S. stercoralis; $11,13 \%$ de A. lumbricoides; $9,96 \%$ de ancilostomideos; $9,57 \%$ de $\mathrm{E}$. histolytica, tendo os outros parasitas apresentado prevalências inferiores às citadas. Todas as crianças que apresentaram ovos de parasitas nas fezes foram tratadas. Os resultados encontrados mostram que a esquistossomose mansoni é um grave problema de saúde pública e que medidas na área do saneamento básico se fazem necessárias para controle da endemia.
\end{abstract}

Palavras-chaves: Prevalência. Esquistossomose mansoni. Parasitas intestinais. Inquérito parasitológico.

A esquistossomose mansoni é endêmica em três continentes: Ásia, África e América. No Brasil, surgiu provavelmente associada ao tráfico de escravos durante o período colonial, sendo encontrada numa faixa contínua que se estende do Rio Grande do Norte até Minas Gerais, além de áreas no Ceará, zonas do agreste nordestino, no Rio de Janeiro, em São Paulo, no Paraná, e de focos isolados no Pará, Maranhão, Piauí, Goiás, Espírito Santo, Santa Catarina e Rio Grande do Sul ${ }^{79}$. Tratase de uma endemia em franca expansão: aproximadamente doze milhões de brasileiros são portadores da parasitose, dos quais pelo menos seis milhões são crianças ${ }^{6}$.

O município de Jaboticatubas, MG, ocupa uma área de $1.124 \mathrm{~km}^{2}$ na região da Serra do Cipó, a 74 km da capital estadual. Sua população, de acordo como último recenseamento, é de 12.720 habitantes,

Departamento de Medicina Preventiva e Social da Faculdade de Medicina da Universidade Federal de Minas Gerais, Belo Horizonte, MG.

Auxílio financeiro: FAPEMIG.

Endereço para correspondência: Prof. Geraldo Cunha Cury. R. Prof. Morais 32/503, Savassi 30150-370 Belo Horizonte, MG. Recebido para publicação em 07/04/94. dos quais dois terços se encontram no meio rural e se dedicamà atividade agropecuária, principalmente à cultura de hortifrutigranjeiros 5 .

Em 1955, com base em exames de fezes realizados pelo método de Hoffman, Pons e Janer (HPJ), foi relatada uma prevalência de $40,5 \%$ de esquistossomose mansoni na população do município ${ }^{1}$, sendo que os fatores físicos e populacionais que fazem de Jaboticatubas uma região repleta de cachoeiras, rios e córregos cortando povoados rurais sem saneamento básico, levaram a SUCAM-MG a incluir esta localidade no Programa Especial de Controle da Esquistossomose (PECE), o qual encontrou uma prevalência de $33,52 \%$ na população estudada (12.044 habitantes) em $1975^{3}$.

O estudo teve os seguintes objetivos: 1) levantamento da prevalência da esquistossomose mansoni e das demais parasitoses em todos os escolares da zona rural do município de Jaboticatubas, de acordo com cada localidade estudada; 2) levantamento sumário das condições de saneamento da população estudada; 3) esclarecimento à população sobre aspectos básicos relacionados as parasitoses prevalentes e seus 
Cury GC, Salles PGO, Reis MCW, Rego VM, Arndt AW, Souza Filho CBA, Moreira HB, Abreu MS, Leite PMG. Prevalência da esquistossomose mansoni e de parasitoses intestinais em escolares da área rural do municipio de Jaboticatubas, MG, 1992-1993. Revista da Sociedade Brasileira de Medicina Tropical 27:217-220, out-dez, 1994.

malefícios, e como elas podem ser evitadas através do saneamento básico; e 4) tratamento dos casos detectados.

\section{MATERIAL E MÉTODOS}

De um total de 864 alunos da primeira à quarta série primária das escolas municipais e vinculadas da zona rural do município, na faixa etária de seis a quinze anos, foram examinados todos os que estiveram presentes nas escolas nos dias em que se realizou o estudo, atingindo-se um total de 512 crianças (representando $59,3 \%$ da população estudada).

Foi realizado levantamento das condições de moradia dos alunos através de questionário no qual foi avaliado o tipo de habitação (alvenaria, adobe ou madeira), a origem da água utilizada no domicílio (córrego ou outra fonte) e a existência ou não de saneamento básico (fossa ou banheiro).

De cada aluno foi colhida uma amostra de fezes em recipiente adequado fornecido pelo convênio SUCAM/Secretaria Municipal de Saúde/Prefeitura Municipal.

Foram realizados exames parasitológicos de fezes nos laboratórios da SUCAM e do Centro de Saúde de Jaboticatubas pelo método HPJ, utilizandose aproximadamente vinte horas de sedimentação. O método Kato-Katz não foi utilizado por não fazer parte da rotina do laboratório.

Após os resultados dos exames de fezes, os escolares foram tratados com medicamentos provenientes da Central de Medicamentos (CEME) por intermédio da Secretaria de Saúde do município. No tratamento da esquistossomose foi utilizado oxamniquina na dose única de $20 \mathrm{mg} / \mathrm{kg}$ de peso, sendo o medicamento ingerido na presença dos estagiários; para a ancilostomíase, ascaridíase, enterobíase e tricuríase foi utilizado mebendazol na dose de $200 \mathrm{mg}$ durante três dias, repetindo após duas semanas; para a estrongiloidíase foi utilizado o cambendazol em dose única de $5 \mathrm{mg} / \mathrm{kg}$; para a heminolepíase foi dado praziquantel dose única de $25 \mathrm{mg} / \mathrm{kg}$; para giardíase e amebíase foi dado metronidazol com $40 \mathrm{mg} / \mathrm{kg}$ em duas tomadas durante dez dias.

Foram também realizadas palestras sobre higiene, saneamento básico e parasitoses especialmente esquistossomose - utilizando-se de material didático fornecido pela Secretaria Municipal de Educação.

\section{RESULTADOS}

$\mathrm{O}$ índice de infecção pelo $S$. mansoni entre os escolares de Jaboticatubas nos anos de 1992-93 foi de $15,43 \%$ (de um total de 512 crianças, 79 apresentaram ovos de $S$. mansoni nas fezes), sendo que 130 não apresentaram ovos de parasita algum nas fezes (Tabela 1).

Para as outras parasitoses, os valores de prevalência encontrados foram $13,87 \%$ ( 71 crianças) para G. lamblia; $12,89 \%$ (66 crianças) para $S$. stercoralis; $11,13 \%$ (57 crianças) para $A$. lumbricoides; $9,96 \%$ (49 crianças) para $E$. histolytica; $5,86 \%$ (30 crianças) para $H$. nana; $3,52 \%$ (18 crianças) para $E$. vermicularis; $0,39 \%$ ( 2 crianças) para $T$. trichiura (Tabela 1 ).

Tabela 1 - Prevalência de parasitoses intestinais em escolares da área rural do município de Jaboticatubas, MG, 1992-93.

\begin{tabular}{llc}
\hline \multirow{2}{*}{ Parasitas } & \multicolumn{2}{c}{ Escolares parasitados } \\
\cline { 2 - 3 } & $\mathrm{n}^{\mathbf{0}}$ & $\%$ \\
\hline S. mansoni & 79 & 15,43 \\
G. lamblia & 71 & 13,87 \\
S. stercolaris & 66 & 12,89 \\
A. lumbricoides & 57 & 11,13 \\
Ancilostomídeos & 51 & 9,96 \\
E. histolytica & 49 & 9,57 \\
H. nana & 30 & 5,86 \\
E. vermicularis & 13 & 3,52 \\
T. trichinra & 2 & 0,39 \\
\hline
\end{tabular}

Casa de Telha e Mato Barreiro foram as localidades em que os escolares apresentaram os maiores índices de infecção pelo $S$. mansoni, com $56,67 \%$ e $57,14 \%$ de prevalência, respectivamente (Tabela 2). Observa-se que estas são das localidades mais carentes conforme os dados apresentados na Tabela 3. As outras localidades mostram índices de infecção entre $1,96 \%$ e 38,46\%.

Quanto à estrutura das casas, foram encontradas $290(61,57 \%)$ casas de alvenaria, $180(38,21 \%)$ de adobee $1(0,22 \%)$ de madeira. Em cinco localidades (Bom Jardim, Casa de Telhas, Mato Barreiro, Rio 
Cury GC, Salles PGO, Reis MCW, Rego VM, Arndt AW, Souza Filho CBA, Moreira HB, Abreu MS, Leite PMG. Prevalência da esquistossomose mansoni e de parasitoses intestinais em escolares da área rural do municipio de Jaboticatubas, MG, 1992-1993. Revista da Sociedade Brasileira de Medicina Tropical 27:217-220, out-dez, 1994.

Tabela 2 - Prevalência de esquistossomose mansoni em escolares da zona rural de Jaboticatubas, $M G, 1992-93$.

\begin{tabular}{lccc}
\hline Localidade & $\begin{array}{c}\mathbf{N}^{\circ} \text { de } \\
\text { alunos }\end{array}$ & $\begin{array}{c}\text { Infectados pelo } \\
\text { S. mansoni }\end{array}$ & $\begin{array}{c}\text { Preva- } \\
\text { lência \% }\end{array}$ \\
\hline Mato Barreiro & 14 & 8 & 57,14 \\
Casa de Telha & 30 & 17 & 56,67 \\
Barreiro & 26 & 10 & 38,46 \\
Pedra Branca & 18 & 6 & 33,33 \\
Jacinto & 15 & 5 & 33,33 \\
Boa Vista & 14 & 4 & 28,57 \\
Outras & 395 & 29 & 7,34 \\
\hline Total & 512 & 79 & 15,43 \\
\hline
\end{tabular}

Vermelho e Santana) o número de casas de adobe é superior ao de casas de alvenaria.

Em relação à origem da água utilizada pela população estudada, $235(49,89 \%)$ casas utilizam \&guas naturais, enquanto $236(50,11 \%)$ utilizam água proveniente de cisternas ou poços. Nas localidades de Bamburral, Bom Jardim, Casa de Telhas, Jacinto, Rio Vermelho, Acudinho, Felipe, Santana, Capão Clemente, Lapinha e Pedra Branca, observa-se que a maior parte das habitações pesquisadas faz uso de águas naturais no seu dia-adia.
O saneamento inexiste em $178(37,79 \%)$ casas, enquanto em $293(62,21 \%)$ casas a população se utiliza de banheiros ou fossas. Foi observada ausência de instalações sanitárias em mais de $50 \%$ das casas das seguintes localidades: Casa de Telhas, Mato Barreiro, Rio Vermelho, Santana, Palma, Ciro Correa L Lapinha. Deve-se deixar claro que nenhuma das localidades estudadas possui rede de esgoto.

\section{DISCUSSÃO}

Diversos autores, desde a década de cinqüenta relatam estimativas de esquistossomose mansoni que variam de $13,9 \%$ a $17,4 \%$ para o estado de Minas Gerais. As estimativas atuais são da ordem de $10 \%$ da população do país infectada pelo $S$. mansoni $i^{2} 610$.

Os dados encontrados entre os escolares em Jaboticatubas, em 1992-93, mostraram uma prevalência para a infecção por $S$. mansoni de $15,43 \%$, o que está de acordo com as estimativas já citadas.

É importante observar que nas localidades mais carentes do município observamos prevalências de até $57,69 \%$. Essas localidades são as que apresentam as piores condições de habitação e saneamento, o que está de acordo com os conhecimentos a respeito

Tabela 3 - Condições de habitação e saneamento de escolares na área rural de Jaboticatubas, MG, 1992-1993.

\begin{tabular}{|c|c|c|c|c|c|c|c|}
\hline \multirow{2}{*}{ Localidade } & \multicolumn{3}{|c|}{ Habitação } & \multicolumn{2}{|c|}{ Origem da água } & \multicolumn{2}{|c|}{ Saneamento } \\
\hline & alvenaria & adobe & madeira & córrego & outra fonte & $\begin{array}{l}\text { banheiro } \\
\text { ou fossa }\end{array}$ & nenhum \\
\hline Açudinho & 3 & 3 & 0 & 4 & 2 & 6 & 0 \\
\hline Bamburral & 44 & 7 & 0 & 26 & 25 & 50 & 1 \\
\hline Bom Jardim & 5 & 6 & 0 & 9 & 2 & 7 & 4 \\
\hline Capão Clemente & 12 & 10 & 0 & 12 & 10 & 14 & 8 \\
\hline Casa de Telha & 12 & 18 & 0 & 20 & 10 & 7 & 23 \\
\hline Ciro Correa & 34 & 13 & 0 & 21 & 26 & 22 & 25 \\
\hline Felipe & 6 & 4 & 0 & 7 & 3 & 5 & 5 \\
\hline Jacinto & 14 & 1 & 0 & 13 & 2 & 15 & 0 \\
\hline Lapinha & 10 & 6 & 0 & 13 & 3 & 5 & 11 \\
\hline Mato Barreiro & 3 & 8 & 0 & 5 & 6 & 4 & 7 \\
\hline Palma & 8 & 4 & 0 & 6 & 6 & 3 & 9 \\
\hline Pedra Branca & 10 & 8 & 0 & 12 & 6 & 10 & 8 \\
\hline Rio Vermelho & 9 & 20 & 0 & 19 & 10 & 2 & 27 \\
\hline Santana & 8 & 15 & 0 & 18 & 5 & 10 & 13 \\
\hline Outras & 112 & 57 & 1 & 50 & 120 & 133 & 37 \\
\hline Total & 290 & 180 & 1 & 235 & 236 & 293 & 178 \\
\hline
\end{tabular}


Cury GC, Salles PGO, Reis MCW, Rego VM, Arndt AW, Souza Filho CBA, Moreira HB, Abreu MS, Leite PMG. Prevalência da esquistossomose mansoni e de parasitoses intestinais em escolares da área rural do municipio de Jaboticatubas, MG, 1992-1993. Revista da Sociedade Brasileira de Medicina Tropical 27:217-220, out-dez, 1994.

da doença.

Ponto importante a ser ressaltado é o fato de que os exames parasitológicos de fezes utilizaram método qualitativo (HPJ) e não o método quantitativo (Kato-Katz), o que impossibilita estudos relacionados à carga parasitária.

A queda observada na prevalênciá da esquistossomose mansoni em Jaboticatubas, entre 1955 e $1992-93$, de $40,5 \%$ para $15,43 \%$ provavelmente foi maior, pois a prevalência obtida em 1955 incluiu a população total; e como foi relatado, a prevalência por grupo etário mostra-se mais elevada até os 15 anos de idade, que foi o grupo etário por nós estudado - portanto, a prevalência na população total deve ser consideravelmente menor que entre as crianças ${ }^{148}$.

Observa-se portanto que a endemia estudada ainda é um grave problema de saúde pública para o município, e embora reduções na prevalência possam ser obtidas através de tratamentos periódicos em larga escala, como observados em Comercinho, MG e Peri-peri, $\mathrm{MG}^{4}{ }^{8}$, somente medidas mais efetivas na área de saneamento básico poderão equacionar o problema.

\section{SUMMARY}

Students from a Rural Boarding house of UFMG School of Medicine performed a survey of prevalence of schistosomiasis mansoni and other intestinal parasites in 20 rural schools in Jaboticatubas, $M G$. An evaluation of house and sanitation conditions was made and stool parasitological examinations were realised in all school children. It was noticed that $15.43 \%$ of the children presented S. mansoni's ova in stool - that was the most prevalent parasite. From the examinations we verify $13.76 \%$ positive cases for $\mathrm{G}$. lamblia; $12.89 \%$ for $\mathrm{S}$. stercoralis; $11.13 \%$ for A. lumbricoides; $9.96 \%$ for hookworms; $9.57 \%$ for $\mathrm{E}$. histolytica. The other parasites appeared with lower prevalence. All the children that presented parasite's ova in stool received treatment. The result that was found shows that schistosomiasis mansoni is a very serious problem of public health and basic sanitation actions are necessary to the endemic control.

Key-words: Prevalence. Schistosomiasis mansoni. Intestinal parasites. Parasitological survey.

\section{AGRADECIMENTOS}

À Secretaria Municipal de Saúde de Jaboticatubas, na pessoa do Dr. Dulio Clark Xavier, pela sua colaboração com o trabalho. À FAPEMIG ( Fundação de Amparo à Pesquisa do Estado de Minas Gerais ) pela concessão de bolsa de iniciação científica.

\section{REFERÊNCIAS BIBLIOGRÁFICAS}

1. Brener $Z$, Mourão OG. Inquéritos clínicoepidemiológicos em focos endêmicos de esquistossomose mansoni em Minas Gerais. Revista Brasileira de Malariologia e Doenças Tropicais, 8:519-526, 1956.

2. Coelho PMZ. S. mansoni. In: Neves DP (ed) Parasitologia Humana, $8^{a}$ edição, Atheneu, São Paulo p.212-223, 1991.

3. Conselho de Desenvolvimento Social. Programa especial de controle da esquistossomose. Imprensa Oficial, Brasîlia, 1976.

4. Cury GC. Estudo clínico-epidemiológico da esquistossomose mansoni em Comercinho, Minas Gerais $(1974,1981,1988)$. Tese de Doutorado, Universidade Federal de Minas Gerais, Belo Horizonte, MG, 1991.

5. Fundação Instituto Brasileiro de Geografia e Estatística. Sinopse preliminar docenso demográfico 1991 - Minas Gerais. IBGE, Riode Janeiro, 1992.

6. Katz N. Controle da esquistossomose no estado de Minas Gerais. Anais da Academia Mineira de Medicina 14(supl):51-66, 1986.

7. Katz N. Possibilidade de controle da esquistossomose. Jornal Brasileiro de Medicina 50:85-88, 1986.

8. Katz N, Rocha RS, Pereira JP. Controle da esquistossomose em Peri-peri (Minas Gerais) através de repetidos tratamentos clínicos e aplicação de molusquicidas. Revista do Instituto de Medicina Tropical de São Paulo 22(supl 4):203-211, 1980.

9. Lambertucci JR, Rocha RS, Carvalho OS, Katz N. A esquistossomose mansoni em Minas Gerais. Revista da Sociedade Brasileira de Medicina Tropical 20:47-52, 1987.

10. Marques AC. O controle das grandes endemias em 1984. Revista Brasileira de Malariologia e Doenças Tropicais 37:77-92, 1985. 